\title{
Experimental analysis of reinforced concrete block masonry walls subjected to in-plane cyclic loading
}

\author{
Vladimir G. Haach ${ }^{1,2}$ \\ Graça Vasconcelos ${ }^{1}$ \\ Paulo B. Lourenço ${ }^{1}$
}

\begin{abstract}
An innovative system for reinforced concrete masonry walls based on the combination of vertical and horizontal trussed reinforcement is proposed. The mechanical characterization of the seismic behavior of such reinforced masonry walls is based on static cyclic tests carried out on panels with appropriate geometry. The evaluation of factors influencing the in-plane cyclic behavior of concrete masonry walls, such as the horizontal reinforcement, pre-compression and masonry bond pattern is performed. The analysis of the results is made through the failure modes and the force vs. displacement diagrams, from which the seismic performance is evaluated based on the ductility and energy capacity dissipation. Results stressed that the increase on the pre-compression level lead to a more rigid and fragile lateral behavior of the masonry walls. The presence of horizontal reinforcement ensures better control and better distribution of cracking, even only a marginal increase of lateral strength was found.
\end{abstract}

Key words: concrete block masonry walls, vertical and horizontal reinforcement, inplane behavior, shear, seismic performance 


\section{Introduction}

In masonry buildings the major structural elements are the masonry walls. When masonry buildings are submitted to seismic loading, out-of-plane failure of the structural walls can prevail if no adequate connection between the walls or between the walls and the floors is achieved. If good connections exist the resisting mechanism to seismic loads is mainly attained by the shear walls. Unreinforced shear walls are the major structural elements in ancient masonry buildings but can also be used in modern masonry if the buildings are located in low seismicity zones. In regions with moderate to high seismicity, reinforced masonry walls are required so that resistance and ductility can be achieved. In fact, serious damages in unreinforced masonry walls were observed in past earthquakes such as in the 1931 Hawke’s Bay in New Zealand, 1976 Friuli in Italy, 1949 Olympia and 1965 Seattle-Tacoma earthquakes, leading to the idea that unreinforced masonry walls behave in an inappropriate manner under seismic loading. The introduction of reinforcements on the walls enables also an improvement on the out-of-plane response of the walls.

Therefore, the understanding of the behavior of unreinforced masonry walls under inplane cyclic loading remains a subject of much interest for researchers and practitioners, (Mahmoud et al., 1995; Zhuge et al., 1996; Bosiljkov et al., 2003; Steelman and Abrams, 2007), not only with respect to rehabilitation and strengthening of existing buildings but also in case new construction where structural masonry is adopted. Reinforced masonry consists of a structural system that can be an alternative to reinforced concrete or steel, with easy application, practical, fast to be build and economically competitive. These elements are subjected to flexure and shear in conjunction with compression associated to the gravity loads. Even if its behavior under 
flexure is well-defined and follows basically the same rules applied to concrete structures, in terms of shear, masonry walls exhibit a more complex behavior due to the presence of weakness planes along head and bed joints.

The failure mode of a shear wall depends on the combination of applied loads, wall geometry, properties of the materials and, as recently pointed out by Vasconcelos (2005), on the masonry bond pattern. According to Tomaževič (1999), when an unreinforced masonry shear wall is subjected to lateral in-plane loading a diagonal crack develops and a severe deterioration of wall strength with brittle collapse occurs. The brittleness of the failure of unreinforced masonry shear walls, which is more remarkable with high axial loads, is reduced by the use of steel reinforcement. According to several authors, the introduction of reinforcement in the masonry ensures the increase on the ductility, and provides better energy dissipation under seismic loading (Schultz et al., 1998; Yoshimura et al., 2003; Voon and Ingham, 2006).

Bed joint reinforcement has been used in masonry construction for many years. This usage dates back to at least 1939 as a good solution to control tensile cracks (Bartlett, 1965). This horizontal reinforcement prevents the separation of the wall with a single discrete crack at shear failure, allowing masonry to carry stresses after cracking (Schultz et al., 1998). Bed joint reinforcement reduces also the crack width, with a positive influence on the distribution of shear stresses (Kubica and Piekarczyk, 2004). Vertical reinforcement combined with horizontal reinforcement allows even better performance of masonry shear walls. The increasing flexural capacity of the walls by insertion of vertical reinforcement is clear (Shing et al., 1989; Voon and Ingham, 2005) but, according to Tomaževič (1999), post-earthquake observations and experiments indicated that only vertical steel reinforcement is not capable of contributing to the 
shear resistance of masonry. Priestley and Bridgeman (1974) reported that vertical reinforcement alone is three times less efficient than combined horizontal and vertical reinforcement in resisting shear loading. According to Khattab and Drysdale (1993), the resistance of shear stresses depends on the distribution of the steel bars between the horizontal and vertical directions.

The present paper aims at providing additional insight on the influence of horizontal and vertical reinforcement in the seismic performance (shear strength, energy dissipation, ductility) of reinforced masonry walls. The experimental research considered eight shear masonry walls, subjected to combined vertical and cyclic horizontal loads, with an innovative truss reinforcement system proposed through a research project co-funded by the concrete block masonry industry.

\section{Experimental Program}

Evaluation of the seismic performance of reinforced concrete block masonry walls was made based on static cyclic tests, where a combination of vertical and cyclic horizontal loads was applied to the wall. The main goal of the experimental research is to obtain failure modes and force-displacement hysteresis loops, and to characterize seismic performance from quantitative indexes such as energy dissipation and ductility.

\subsection{Test Specimens}

A total of eight concrete block masonry walls were tested. The reinforcement details for the eight walls are summarized in Table 1 . Here, $\mathrm{Bi}(\mathrm{i}=1,2)$ represents the masonry bond pattern, detailed below, $\phi_{v}$ and $\phi_{h}$ is the diameter of longitudinal bars of 
the vertical and horizontal reinforcement respectively, $\rho_{v}$ and $\rho_{h}$ are the associated reinforcement ratios and $\sigma$ is the normal stress. The specimens are denoted by $\mathrm{Nx}-\mathrm{Bi}-\mathrm{y}$, where $\mathrm{x}$ indicates the vertical pre-compression force in $\mathrm{kN}$, $\mathrm{i}$ is the adopted bond pattern type and y is an optional distinct characteristic. This optional characteristic is UM, for unreinforced masonry, SH, for only horizontal reinforcement, PA, for lower horizontal reinforcement, and MA, for higher horizontal reinforcement.

Due to the limitations of the laboratory facilities in terms of actuators capacity, reduced scale (1:2) concrete masonry units, specifically developed for the research project, were used in the tested masonry panels. Special care was taken with the granulometry of materials used in production of the units since the shells and webs of these units had a small thickness. Three hollow cell concrete units of 201mm(length) x 93mm(thickness) x 100mm(height) were considered in the experimental program. These units have two cells with $60 \mathrm{~mm} \times 70 \mathrm{~mm}$ and one small cell in the middle of unit with $15 \mathrm{~mm} \times 70 \mathrm{~mm}$, where vertical reinforcement was located. The percentage of holes in the block is about $46 \%$, which, according to Eurocode 6 (2005), indicates that the units belong to group 2 .

Pre-fabricated trussed reinforcement composed by two longitudinal bars connected by diagonal bars was used for vertical and horizontal reinforcement. Two different masonry bond patterns were considered for the masonry specimens so that different construction techniques could be evaluated. Masonry bond pattern B1 corresponds to a typical running masonry bond pattern (units were overlapped on consecutive courses), see Fig. 1a. This masonry bond pattern enables the positioning of the vertical reinforcement in the frogged ends of the three cell masonry units and in the internal hollow cell. In the second masonry bond pattern (B2), the vertical reinforcement are 
placed only in the vertical core defined by the frogged ends of the units, defining a continuous vertical joint, see Fig. 1b. The latter masonry bond pattern is not typical and is being studied at University of Minho since it has advantages concerning the construction technology, as the masonry units can be laid after the placing of the reinforcement without any change on the traditional constructive technique applied in the construction of unreinforced masonry walls. It is noted that the hollow cell where the vertical reinforcement was positioned was completely filled at each course with the same mortar used for the laying of the masonry units, in order to avoid the use of an additional material in the building system. The filling of the internal reinforced cores is essential to attain an adequate bond between the reinforcements and masonry.

The walls tested have a length of 1206mm for masonry bond pattern B1 and 1208mm for bond pattern B2, with six full units per masonry course, and a height of $800 \mathrm{~mm}$, with ten masonry courses, corresponding to an aspect ratio of 0.67 . This geometry was adopted so that shear could prevail in the lateral response of the masonry wall specimens.

Besides the masonry bond pattern, other variables were analyzed, namely the precompression level and the vertical and horizontal reinforcement ratios. The distance between the longitudinal bars of the trussed type reinforcement was $50 \mathrm{~mm}$ and $80 \mathrm{~mm}$ for the vertical and horizontal reinforcement, respectively, which allowed the positioning of vertical trussed reinforcement inside the horizontal trussed reinforcement. The percentage of vertical reinforcement ( $\rho_{v}=0.098 \%$ ) was kept constant for all walls with the exception of specimen N60-B1-UM (unreinforced masonry wall) and specimen N60-B1-SH, which only has horizontal reinforcement. The adoption of the reinforcement ratios and spacing of bars was based on the suggestions given in 
Eurocode 6 (2005) and Eurocode 8 (2003) and obviously based on limitated dimensions of the specimens. Two levels of vertical pre-compression are considered, corresponding to a normal stress level of $0.56 \mathrm{MPa}$ and 1.30MPa.

Reinforced concrete beams were placed at the bottom (280 mm x 280 mm x 1400 $\mathrm{mm}$ ) and at the top (280 $\mathrm{mm} \times 280 \mathrm{~mm} \times 1200 \mathrm{~mm}$ ) of the walls in order to anchor the vertical reinforcement and ensure an uniform distribution of the applied vertical and horizontal loads. Walls were built by the same experienced mason under adequate supervision and were cured in laboratory environmental conditions. In order to ensure similar curing conditions, the tests were carried out at an age of 28 days.

\subsection{Test setup, instrumentation and procedure}

Masonry shear walls are usually submitted to combined in-plane horizontal and vertical loading in experimental programs so that the weight of the upper storeys can be accounted for. According to Tomaževič (1999), in reality the axial compression load changes during earthquakes due to restraints that prevent the rotation of the wall at large displacements. However, due to the difficulty of simulating the real boundary conditions, the walls are usually tested with constant vertical load.

The test setup for the cyclic tests in the present program was performed as shown in Fig. 2. The bottom reinforced concrete beam of the wall was fixed to a steel profile through eight steel bolts and two adjustable clamping angles to avoid uplift and slippage of the base. In turn, the steel profile was connected to the strong floor through steel rods. The axial load was applied by using a vertical actuator with vertical steel cables anchored at the strong floor. A stiff steel beam was used for the distribution of the vertical load and a set of steel rollers was placed to allow relative displacement of the 
wall with respect to the vertical actuator. A rubber layer was placed between the steel profile and the top of the concrete beam to provide a better distribution of stresses. The horizontal load was transmitted to the wall by means of two steel plates fixed at the top concrete beam, using an actuator with two hinges.

The displacements of the wall under cyclic loading were measured by means of a set of LVDTs as indicated in Fig. 3a. LVDTs 1, 2 and 3 measured the lateral deformation of the wall. LVDTs 4 and 5 measured the slippage and uplift of the base of the wall respectively, and LVDTs 6 and 7 measured the rotation of the top concrete beam. LVDTs 8 and 9 recorded the diagonal crack openings of the wall indicating also possible rigid body movements along the diagonal cracks. The vertical LVDTs 10, 11, 12 and 13 were fixed to both sides of the wall in order to obtain the Young's modulus of masonry, during the process of applying vertical loading. LVDTs 1, 2, 3, 4 and 5 were fixed to an external steel frame to ensure a fixed reference for measurements. In addition, strain-gauges were glued to the reinforcement at different locations, aiming at evaluating their contribution to the response of the wall, see Fig. 3b. For specimens N150-B1 and N150-B2, strain gauges were also glued in the top and bottom horizontal reinforcement, at the same positions as indicated in Fig. 3b.

The testing procedure was divided in two phases. First, a vertical load of $100 \mathrm{kN}$, corresponding approximately to $15 \%$ of the compressive strength, was applied at a rate of $0,25 \mathrm{kN} / \mathrm{s}$, in order to evaluate the Young's modulus of the wall. Afterwards, the wall was unloaded and reloaded up to a vertical stress equal to $1,30 \mathrm{MPa}$ or $0,56 \mathrm{MPa}$ depending on the selected level of pre-compression, which was kept constant during the test. Horizontal displacements were imposed to the walls following displacement-time histories as shown in Fig. 4. The cyclic tests were carried out under displacement 
control at a rate of $70 \mu \mathrm{m} / \mathrm{s}$ by means of an external LVDT connected to the horizontal actuator.

\subsection{Material Properties}

The mechanical properties of the materials, namely units, mortar, reinforcement and masonry as a composite material, were obtained through a set of experimental tests. The normalized compressive strength of the three cell concrete blocks was obtained according to EN772-1 (2000) being the average value 12.1MPa. The Young's modulus of the concrete blocks was derived from the compressive stress-strain diagrams, being the average value 9.6 GPa. The same mortar was applied for the filling of reinforced internal cores and for the laying of masonry units, following a previous study to define a mortar mix with an adequate consistence to use as embedding and as infill material (Haach et al., 2007). As in case of the production of units, special care was also taken with granulometry of the sand used in mortar mix in order to ensure a proper relation between the maximum diameter of the aggregates and the thickness of joints. A general purpose mortar was adopted composed by cement and fine sand in proportion 1:3 (cement/sand) in volume with water/cement ratio equal to 0.90 , corresponding to an average flow table diameter of 180mm, measured according to EN1015-3 (1999). During the construction of the walls, three specimens of mortar (40 mm x $40 \mathrm{~mm}$ x 160 $\mathrm{mm}$ ) were cast aiming at controlling the quality of the material through the compressive, $f_{m}$, and flexural strength, $f$ fl, obtained according to EN1015-11 (1999). The mortar specimens were tested with the same age of the walls, see Table 2 for results.

The characterization of masonry as a composite material was carried out by means of uniaxial compressive tests and diagonal tests following EN1052-1 (1999) and ASTM 
E519-02 (2000), respectively. Average values of 5.95 MPa and 10.5 GPa were obtained for the compressive strength and Young's modulus in masonry wallets respectively. It should be stressed that a good performance have been obtained in case of the internal cores of the masonry are filled with mortar, according to a previous experimental study based on uniaxial compressive tests on masonry wallets with and without filled central internal cells (Haach et al., 2008).

Average values of shear strength and shear modulus of $0.19 \mathrm{MPa}$ and $1.85 \mathrm{GPa}$ were obtained from diagonal tests. In case of reinforcement, three samples were submitted to direct tensile tests, being the average value of the yield stress $580 \mathrm{MPa}$ and of Young's modulus $196 \mathrm{GPa}$.

The Young's modulus of the walls ( $E_{a}$, exp), obtained from the vertical LVDTs attached to central part of the wall are given in Table 2. These results are of relevance to analyze the horizontal force-displacement of the walls. Note that this Young's modulus refers to the wall and not to the masonry material, since in most specimens there was vertical reinforcement and partial filling of masonry cells with mortar.

\section{Results}

\subsection{Failure modes and force-displacement hysteresis diagrams}

Fig. 5 illustrates wall cracking patterns at the end of testing for all specimens. In general, the walls exhibited a mixed shear-flexure failure mode. Horizontal flexural cracks appeared at first or second courses from the bottom due to increasing tensile stresses associated to the flexure of the wall. This damage basically depends on the tensile bond strength of the unit-mortar interface. As the lateral displacement increased, 
the length of the horizontal cracks tended to increase leading to the translation of the neutral axis and thus to the reduction of the effective resistant shear length. At this stage, strains of the vertical reinforcement increased significantly, demonstrating its effective role in the bearing of the tensile stresses due to flexure, avoiding the uplift of the base of wall. With the increase on the imposed lateral displacements, diagonal cracks developed mostly in mortar joints and could be clearly detected by the diagonal LVDTs. The opening of the diagonal cracks and the development of horizontal tensile stresses was followed by increasing strains detected on the strain gauges attached at mid length of the horizontal reinforcement in the central region of the wall. The additional strain gauges located in horizontal reinforcement at the top and bottom of specimens N150-B1 and N150-B2 measured no significant strains, meaning that only negligible strains developed in these bars.

The diagonal crack opening increased for successive imposed lateral displacements and the wall tended to separate itself in two parts. The stress transfer between both parts of the wall was achieved by the horizontal reinforcement, and vertical reinforcement. The concentration of compressive stresses at the base of wall generated toe crushing in all specimens. In the case of specimens N150-B1 and N150B2, to which a high level of vertical compression was applied, this damage was more evident and led to a sudden collapse of the walls. In the other specimens, toe crushing was followed by a slight sliding of the upper part of the wall over horizontal and/or diagonal cracks as indicated in Fig. 5, where the main macro-crack over which sliding developed is shown.

The lateral load-lateral displacement diagrams of all specimens are shown in Fig. 6, 7 and 8 . The behavior of the walls can be characterized by three critical points: 
opening of flexural cracking, opening of diagonal cracking and crushing of the bottom corners, see Table 3. Flexural cracking loads were obtained based on strain-gauges located in vertical reinforcement and on rotations of the top of the walls measured by LVDTs 6 and 7. Diagonal cracking loads were obtained based on strain-gauges located in horizontal reinforcement and on the measurements of diagonal LVDTs 8 and 9. In general, neither vertical nor horizontal reinforcement did not influence the flexural cracking lateral force, which was about $20 \mathrm{kN}$ for the walls with lower pre-compression and was about $40 \mathrm{kN}$ for the walls with higher pre-compression. Specimens N60-B1UM and N60-B1 exhibited the lowest values of flexural cracking load, which is related to the lower strength of the mortar.

Differently from flexural cracking, diagonal cracking was clearly influenced by the presence of vertical reinforcement. The introduction of vertical reinforcement in masonry walls delayed the formation of the diagonal cracks. In reinforced walls the diagonal cracks developed for .an horizontal force at least $20 \%$ higher than the one recorded in the unreinforced specimen. On the other hand, as observed by other researchers, horizontal reinforcement has no influence on the lateral force level for which diagonal cracking develops (Shing et al., 1989; Schultz et al., 1998; Voon and Ingham, 2005). Pre-compression level also influenced the diagonal cracking by increasing the corresponding horizontal loading in more than $100 \%$.

The introduction of vertical reinforcement increased the lateral strength of specimens at least 50\%, confirming that they effectively improved the flexural behaviour of walls and thus the tensile strength of masonry. In case of horizontal reinforcement, the yield stress was reached only in specimens N60-B1-MA, N60-B1-PA and N150-B2 during the post-peak regime, leading to the breakage of the welding 
between longitudinal and diagonal bars, or to the breakage of longitudinal bars. From Fig. 9a, it is clear that the force carried out by reinforcements is lower than the yield force, when the masonry walls reached the maximum load. Yielding occurs only after peak load, associated to the increase of lateral displacements. Horizontal reinforcement of wall N60-B1-SH (with horizontal reinforcement only) shows the lowest stress with respect to the yielding strength (25\%). This is due to the predominant crack pattern developed in this wall, composed by a single flexural horizontal crack located at first course from the bottom, over which some level of sliding develops at the end of the test. This behavior is confirmed by the significant permanent displacements of the forcedisplacement diagram for this wall, indicated in Fig. 6. The wide horizontal crack occurred due the absence of vertical reinforcement that in the other walls prevent the progression of the flexural crack.

Therefore, the contribution of the horizontal reinforcement to the global lateral response of the walls was in this case low, which is also confirmed by the maximum efficiency of the horizontal reinforcement indicated in Fig. 9b. The low contribution of the horizontal reinforcements appears to be related to the toe crushing failure mode. Here, the efficiency of the horizontal reinforcement in the global lateral response of the wall was calculated as the ratio between the force carried out by the reinforcement, $H_{s}$ and the maximum lateral force of the wall, $H_{\max }$ The force in the reinforcement is calculated based on the strains measured in the strain gauges. It is observed that apart from walls N60-B1 and N60-B1-MA, which exhibited an efficiency of about 23\%, all other walls present an efficiency lower than $13 \%$.

To sum up, it is believed that the modest contribution of the horizontal reinforcements to the lateral response of the concrete block masonry walls is to great 
extent associated to toe crushing predominant failure mode. The predominant flexural behavior of the walls is also confirmed by comparing the experimental results and the analytical flexural strength calculated through the simple flexural theory. Apart from specimens N60-B1 and BN60-B2, which present maximum strength 22\% and 3\% lower than the expected, all other walls presented a higher maximum load slightly higher than the theoretical flexural strength. This result confirms the adequate experimental performance of the innovative solutions proposed.

\subsection{Evaluation of seismic performance}

\subsubsection{Stiffness degradation and energy dissipation}

Stiffness degradation and energy dissipation are important parameters within the scope of the modeling of the cyclic response of the walls as well as for the evaluation of the seismic performance of the walls.. Unless rocking mechanism prevails in the response of walls submitted to in-plane cyclic loading, it is usual that stiffness degradation occurs during reversed cyclic load. As horizontal forces are distributed through the shear wall based in their stiffness, in seismic assessment it is important to predict the stiffness degradation at the ultimate limit state. Since the degree of stiffness degradation is dependent on the damage of the wall, secant stiffness $\left(K_{s, i}\right)$ of each cycle was calculated aiming at evaluating the evolution of damage during loading. The secant stiffness at each loading cycle $K_{s, i}$ was calculated according to the following equation:

$$
K_{s, i}=\frac{H_{\text {máx }, i}}{d_{\text {máx }, i}}
$$


Here, $H_{\max , i}$ is the peak lateral load of the $\mathrm{i}$-cycle and $d_{\text {Hmax }}$ is the displacement corresponding to peak lateral load of the i-cycle.

For the evaluation of the seismic performance, only the quadrant relative to negative horizontal force e negative displacements of the hysteresis diagrams was considered as minor differences between positive and negative secant stiffness for the same cycle were observed.

The capacity of the walls to dissipate energy is also an important parameter in the analysis of their cyclic response. This capacity was evaluated through the coefficient of equivalent viscous damping $(\xi)$, calculated as the ratio between dissipated energy $\left(E_{\text {diss }}\right)$, and total the energy transferred to the system during the loading process designated by input potential energy ( $\left.E_{\text {inp }}\right)$, see Fig. 10.

According to Fig. 11, it is observed that all walls exhibit decreasing secant stiffness as the lateral displacement increases, following a power function. Up to $40 \%$ of the lateral displacement corresponding to the lateral maximum load $\left(d_{\operatorname{Hmax}}\right)$, it is possible to recognize some differences among the walls. Walls submitted to the highest level of pre-compression and the unreinforced masonry wall present the lowest stiffness degradation, approximately of $55 \%$ to $0.40 d_{\text {Hmax. }}$ On the other hand, the walls with horizontal reinforcement, particularly N60-B1-MA and N60-B1-SH, presented the highest stiffness degradation, $90 \%$ and $80 \%$ to $0.40 d_{\text {Hmax }}$ respectively, which, in the latter case, is associated to a sliding failure mechanism. Tomaževič (1999) also pointed out that stiffness degradation of masonry walls under in-plane cyclic loading follows a power function according to the (Eq. 2):

$$
\left(\frac{K_{s, i}}{K_{e}}\right)=\alpha \times\left(\frac{d_{H_{\text {máx,i }}}}{d_{H_{\text {máx }}}}\right)^{\beta}
$$


Here, the stiffness degradation index is defined as the ratio between the secant stiffness in each cycle $K_{s, i}$ to the elastic stiffness, $K_{e}$, as a function of two parameters of degradation $\alpha$ and $\beta$ and of the relation between the maximum displacements at each cycle, $d_{H \max , i}$, and maximum displacement corresponding to the peak lateral load, $d_{H \max }$. A simpler definition is possible if the secant stiffness degradation index is calculated as the ratio between the secant stiffness at each cycle, $K_{s, i}$, and the secant stiffness corresponding to the maximum lateral load, $K_{s}$, as only one damage parameter is needed for adjustment, $\gamma$ :

$$
\left(\frac{K_{s, i}}{K_{s}}\right)=\left(\frac{d_{H_{\text {máx }, i}}}{d_{H_{\text {máx }}}}\right)^{\gamma}
$$

Parameter $\gamma$ was obtained by regression analysis of experimental curves and in general ranged from 0.41 (N60-B1-UM) to 0.57 (N60-B2), except for specimen N150B1, where the value 0.27 indicates low stiffness degradation, as explained above.

Apart from the specimens with the highest pre-compression level, which practically did not dissipate energy in the first cycles, the other masonry walls exhibited a very similar behavior in terms of energy dissipation, as observed in Fig. 12. The coefficient of equivalent viscous damping $(\xi)$ ranged from $40 \%$ to $50 \%$ until the ultimate load. It should be stressed that a moderate increase of energy dissipation occurs after a displacement of about $50 \%$ of the lateral peak load displacement, indicating that moderate damage occurs before peak load is reached. In this stage of loading specimens N60-B1-PA and N60-B1-MA exhibited a mean of $\xi 6 \%$ and $10 \%$ higher than unreinforced specimen, respectively. It is after the ultimate load that energy dissipation increases considerably. In particular, specimens N60-B1-SH and N60-B1-PA presented 
a sudden increase of the viscous damping exhibiting a mean of $\xi 16 \%$ and $26 \%$ higher than unreinforced specimen, respectively. This increasing is associated to the high dissipation of energy due to the tendency of walls to slide along the horizontal crack for the first wall and the breakage of the horizontal reinforcement for the second wall. Introduction of horizontal reinforcement increased the energy dissipation. However, the influence of variation of horizontal reinforcement ratio was not clear.

\subsubsection{Bi-linear diagrams and ductility of the walls}

Earthquakes are responsible for series of cyclic horizontal actions, which often lead to large bending and shear stresses in structural walls, exceeding the range of elastic behavior of masonry materials. Besides the ultimate load capacity, structures subjected to seismic actions should exhibit proper deformation capacity and energy dissipation to resist the inertial efforts imposed by earthquakes and thus to mitigate brittle failures.

In order to simplify the analysis and design, several authors considered idealized bilinear envelopes for force vs. displacement envelops resulting from the cyclic in-plane experimental behavior in order to evaluate its seismic performance (Magenes and Calvi, 1997; Bosiljkov et al., 2003; Vasconcelos, 2005), see Fig. 13. The bilinear diagrams are obtained from the energy equivalence criterion by equalizing the energy under the monotonic experimental envelop and the energy under the bilinear idealized envelop, allowing to define the ultimate displacement $d_{u}$ and the elastic displacement $d_{e}$. Through the bi-linear idealization of force-displacement diagram it is possible to determine the ductility of the wall, which is an essential property of structures subjected to cyclic loads. The ductility factor is defined as the ratio: 
$\mu=\frac{d_{u}}{d_{e}}$

Table 4 shows the results of bilinear idealization of masonry walls. It is seen that the average value of $H_{u} / H_{\text {máx }}$ is 0.84 , which is slightly lower than the value of 0.9 given by Tomaževič (1999). This means that during the seismic analysis the horizontal capacity of the walls should be reduced of $15 \%$, if the bilinear idealization is used. It should be stressed, at this point, that the ultimate resistance $H_{u}$ does not represent the design, but the idealized maximum experimental value. By comparing the values of ductility among the walls it is observed that reinforcement clearly increases the ductility of the walls in at least $30 \%$, for low to moderate pre-compression values. For the walls subjected to the highest level of pre-compression (N150-B1 and N150-B2), the ductility found was similar to the ductility recorded in the unreinforced wall with low precompression value. The increase in the brittleness of the walls with increasing normal stress has been also reported by Shing et al. (1989). The concentration of compressive stresses at the bottom corners leads to the toe crushing, which is followed by the buckling of the vertical reinforcement, avoiding the development of tensile stresses in the reinforcement and leading to the lower contribution to the global response of the walls. This behavior can be also attributed to the brittleness of the concrete units.

An interesting result regarding the masonry bond pattern was the higher stiffness and ductility of masonry specimens built with masonry bond pattern B2. Specimens under pre-compression equal to $0.56 \mathrm{MPa}$ exhibited an increasing of $15 \%$ and $33 \%$ in stiffness and ductility, respectively. In case of specimens under pre-compression equal to $1.30 \mathrm{MPa}$ exhibited an increase of $37 \%$ and $40 \%$ in stiffness and ductility, respectively. This result appears to confirm the reasonable mechanical performance of 
the continuous masonry joint under in-plane cyclic loading, which demonstrates that the proposed simpler construction technology can be an effective alternative solution for reinforced masonry walls.

In Table 4 the experimental elastic stiffness, $K_{e}$, is compared with the theoretical value given by the following expression:

$$
K_{e, \text { theo }}=\frac{G A_{w}}{1.2 h\left[1+3.33 \frac{G}{E}\left(\frac{h}{l}\right)^{2}\right]}
$$

Here $G$ and $E$ are the transversal and longitudinal elastic modulus, $A_{w}$ is the transversal area of the wall, $h$ is the height of the wall and $l$ is the length of the wall.

As observed by Bosiljkov et al. (2005) the use of Eq. 5 does not provide reliable results to lateral stiffness due to the strong anisotropic behavior of masonry. In case of this study, a considerable overestimation of the lateral stiffness results from the use of Eq. 5.

\section{Summary of the parameters influencing the behavior of walls}

The global analysis of the results of the cyclic in-plane tests on concrete block masonry walls allows to conclude that the combination of vertical and horizontal reinforcement leads to an improvement on its in-plane cyclic performance. Specimens reinforced simultaneously with vertical and horizontal trussed-bars exhibited an increase on both lateral strength and deformation capacity, with respect to unreinforced masonry walls, even if the efficiency of horizontal reinforcement is low.

In general, the results indicated that the tested walls presented similar features to the typical reinforced masonry walls, whose results are available in literature. As 
pointed out by Shing et al. (1989) and Schultz et al. (1998), the influence of the percentage of horizontal reinforcement in lateral strength appeared to be not clear, see Fig. 14. The wall with a smaller amount of horizontal reinforcement (N60-B1-PA) presented higher lateral strength than specimen with the intermediate amount of horizontal reinforcement (N60-B1). Additionally, it was possible to observe that the increase of the bed joint reinforcement and the reduction of the vertical spacing in specimen N60-B1-MA resulted in cracking more distributed, higher strength, gradual stiffness degradation and significant increase on the ductility factor. This result is in agreement with Voon and Ingham (2005), which reported that the closely spaced shear reinforcement enables the distribution of stresses throughout the wall diagonals after the shear crack initiation, avoiding diagonal crack localization.

Concerning the vertical pre-compression, an increase on the lateral strength and a reduction on the lateral deformation with an increase on the brittleness, given by a decrease on the lateral deformation and dissipation of energy, were found in the wall specimens submitted to the highest level of normal stresses, see Fig. 15. Again, this is in agreement with the results of several researchers (Shing et al., 1989; Zhuge et al.,1996; Vasconcelos, 2005). In addition, the higher level of pre-compression delays the initial flexural cracking at bed joints, as observed by Voon and Ingham (2005).

With respect to the masonry bond pattern, it was seen that no significant differences in the mechanical behavior were observed for the two adopted bond patterns, even if the non-staggered (reinforced) vertical joint appeared to result in a slight increase on the lateral strength, see Fig. 15. This means that the best masonry bond pattern in terms of construction technology of reinforced masonry walls, i.e. non-staggered bond pattern, presents similar mechanical performance to traditional running masonry bond pattern. 


\section{Conclusions and final remarks}

An innovative system for reinforced concrete masonry walls based on the combination of vertical and horizontal trussed reinforcement was proposed. In order to evaluate the seismic performance of these walls, an experimental program based on inplane static cyclic tests on masonry specimens was defined and parameters such as percentage of reinforcement, masonry bond pattern and vertical pre-compression were varied. The cyclic behavior of the masonry walls was analyzed based on the crack and failure patterns, force-displacement diagrams from which the monotonic envelops and energy dissipation capacity and coefficient of viscous damping were derived, providing also the necessary information for the definition of the bi-linear idealized diagrams that enable the evaluation of the ductility of the walls. From the experimental analysis the main following conclusion can be drawn:

(a) Masonry bond pattern has no significant influence on the overall behavior of the proposed reinforced walls, which means that the easier construction technology can be a reasonable solution;

(b) The vertical pre-compression influences the behavior of the reinforced concrete block masonry walls. Higher values of normal stresses are associated to higher values of lateral strength but more fragile behavior leading to the reduction of the reinforcement efficiency;

(c) The effectiveness of the horizontal reinforcement appears to be related with the presence of vertical reinforcement. If vertical reinforcement is present, initial flexural cracking is limited, which enables the progression and development of diagonal cracking. On the other hand, the variation of the percentage of horizontal reinforcement 
seems not to improve the lateral strength. However this behaviour may be influenced by the toe crushing failure of the walls. Crack localization appears to be avoided by the presence of horizontal reinforcement, enabling a more smeared crack distribution in the walls, and larger nonlinear lateral deformations.

\section{Acknowledgements}

This work was partly supported by contract DISWALL - "Development of innovative systems for reinforced masonry walls”- COOP-CT-2005-018120 from the European Commission. The first author was supported by the Programme Al $\beta$ an, the European Union Programme of High Level Scholarships for Latin America, Scholarship $n^{0}$ E06D100148BR. 


\section{References}

ASTM E519-02: Standard Test Method for Diagonal Tension (Shear) in Masonry Assemblages, 2000.

Bartlett, W. H. (1965). “Masonry wall reinforcement-When, where, how much?”, C/M Magazine, 4pp.

Bosiljkov, V.; Page, A., Bokan-Bosiljkov, V., Žarnić, R. (2003). "Performance based studies of in-plane loaded unreinforced masonry walls”, Masonry International, 16(2), 39-50.

Bosiljkov, V.; Totoev, Y. Z., Nichols, J. M. (2005). "Shear modulus and stiffness of brickwork masonry: An experimental perspective”, Structural Engineering \& Mechanics, 20(1), 21-43.

EUROPEAN STANDARD. EN 772-1, Methods of tests for masonry units - Part1:

Determination of compressive strength. 2000.

EUROPEAN STANDARD. EN 1015-3, Methods of test for mortar for masonry: Part 3: Determination of consistence of fresh mortar (by flow table), 1999.

EUROPEAN STANDARD. EN 1015-11, Methods of tests for mortar for masonry Part 11: Determination of flexure and compressive strength of hardened mortar. 1999. EUROPEAN STANDARD. EN 1052-1, Methods of test for masonry - Part1: Determination of compressive strength. 1999.

EUROPEAN STANDARD. EN 1996-1-1, Eurocode 6: Design of masonry structures, 2005. 
EUROPEAN STANDARD. prEN 1998-1, Eurocode 8: Design of structures for earthquake resistance, Part 1: General rules, seismic actions and rules for buildings, 2003.

Haach, V.G.; Vasconcelos, G.; Lourenço, P. B.; Mohamad, G. (2007). “Study of a mortar to use as infill and embedding”, Proceedings of 10th North American Masonry Conference, St. Louis, Missouri, USA, 530-541.

Haach, V.G.; Vasconcelos, G.; Lourenço, P. B.; Mohamad, G. (2008). “Influence Of The Mortar On The Compressive Behavior Of Concrete Masonry Prisms”, Proceedings of 7th National Congress in Experimental Mechanics, Vila Real, Portugal.

Khattab, M. M.; Drysdale, R. G. (1993). “The effect of reinforcement on the shear response of grouted concrete masonry”, TMS Journal, 12(1), 38-44.

Kubica, J.; Piekarczyk, A. (2004). “Tests of vertically sheared clay brick masonry walls with and without bed joint reinforcement”, Proceedings of 13th International Brick and Block Masonry Conference, Amsterdam, Netherlands, 10pp.

Magenes, G.; Calvi, G. M. (1997). “In-Plane seismic response of brick masonry walls”, Earthquake engineering and structural dynamics, 26(11), 1091-1112.

Mahmoud, A.D.S.; Hamid, A.A.; El Mags, S. A. (1995). "Lateral response of unreinforced solid masonry shear walls: an experimental study”, Proceedings of 7th Canadian Masonry Symposium, Hamilton, Ontario, Canada, 110-125.

Priestley, M. J. N. Bridgeman, D. O. (1974). “Seismic resistance of brick masonry walls”, Bulletin of the New Zealand National Society for Earthquake Engineering, 7(4), 167-187. 
Schultz, A.E.; Hutchinson; R.S., Cheok, G.C. (1998). “Seismic performance of masonry walls with bed joint reinforcement”, Proceedings of Structural Engineers World Congress, San Francisco, California, USA, paper n ${ }^{\circ} 40$.

Shing, P. B.; Noland, J. L.; Klamerus, E., Spaeh, H. (1989). “Inelastic behaviour of concrete masonry shear walls”, Journal of Structural Engineering, 115(9), 2204-2225. Steelman, J.; Abrams, D. P. (2007). “Effect of axial stress and aspect ratio on lateral strength of URM shear walls”, Proceedings of 10th North American Masonry Conference, St. Louis, Missouri, USA, 849-859.

Tomaževič, M. (1999). “Earthquake-resistant design of masonry buildings”, Imperial College Press, London.

Vasconcelos, G. (2005). “Experimental investigations on the mechanics of stone masonry: Characterization of granites and behaviour of ancient masonry shear walls”, PhD Thesis, University of Minho, Guimarães, Portugal. Available from www.civil.uminho.pt/masonry.

Voon, K.C., Ingham, J.M. (2005). “Experimental study of partially grouted concrete masonry walls with openings”, Proceedings of 10th Canadian Masonry Symposium, Banff, Alberta, Canada, 10pp.

Voon, K.C., Ingham, J.M. (2006). “Experimental in-plane shear strength investigation of reinforced concrete masonry walls”, Journal of Structural Engineering, 132(3), 400408.

Yoshimura, K., Kikuchi, K., Kuroki, M., Nonaka, H., Kim, K.T., Matsumoto, Y. Itai, T., Reeznag, W., Ma, L. (2003). “Experimental study on reinforcing methods for confined masonry walls subjected to seismic forces”, Proceedings of 9th North American Masonry Conference, Clemson, South Carolina, USA, 89-100. 
Zhuge, Y.; Corderoy, J.; Thambiratnam, D. (1996). "Behavior of unreinforced brick masonry under lateral (cyclic) loading”, TMS Journal, 14(2), 55-62. 


\section{List of captions for illustrations}

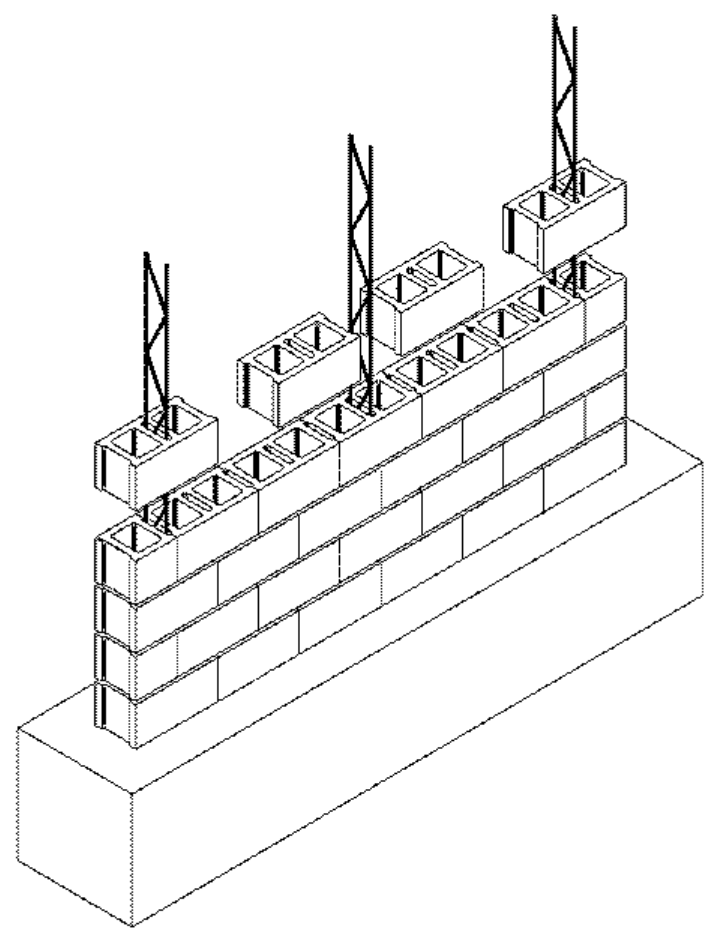

(a)

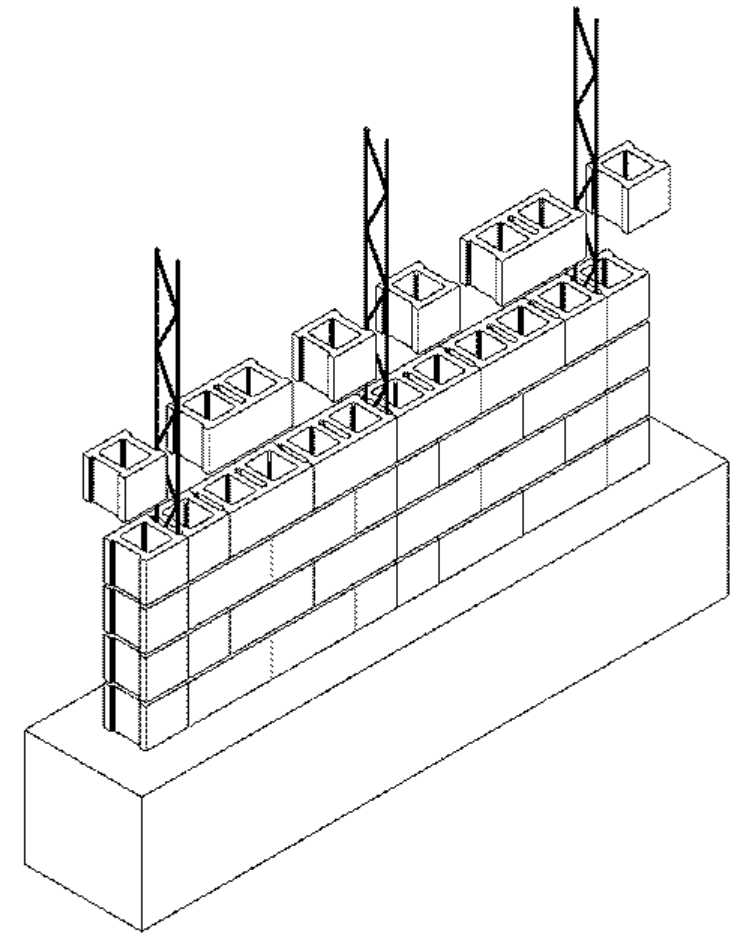

(b)

Fig. 1 - Typology of masonry bond patterns: (a) running masonry bond pattern, B1 (b) bond pattern with continuous vertical joint, B2. 


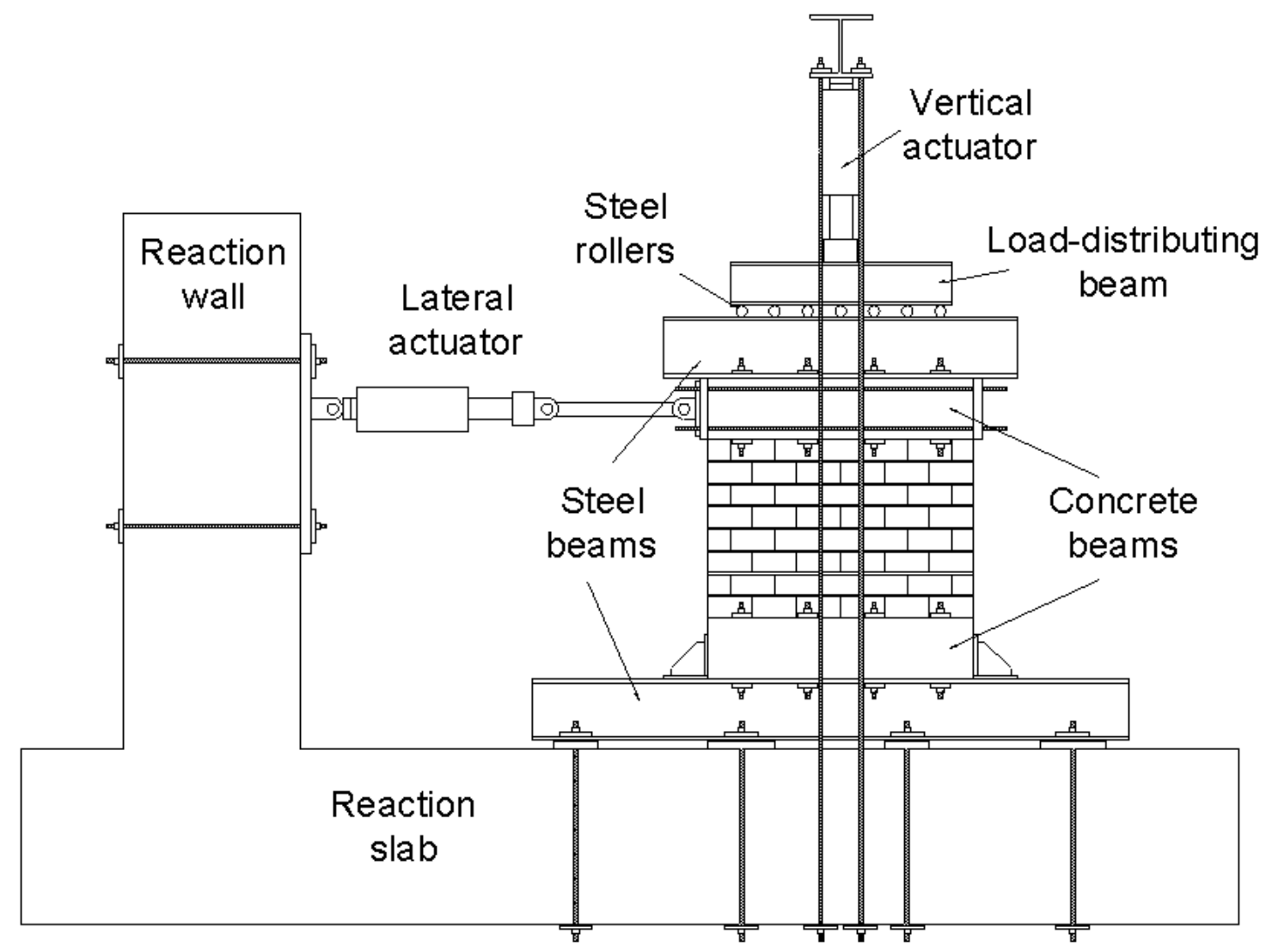

Fig. 2 - Test setup for in-plane cyclic horizontal load.

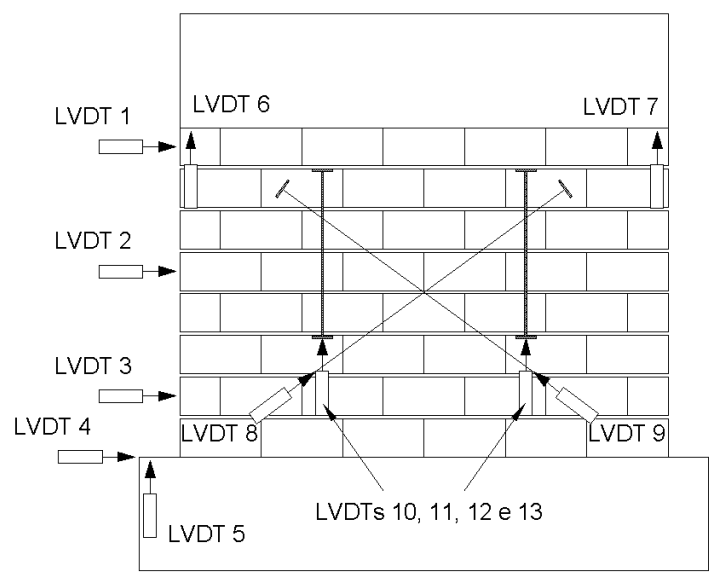

(a)

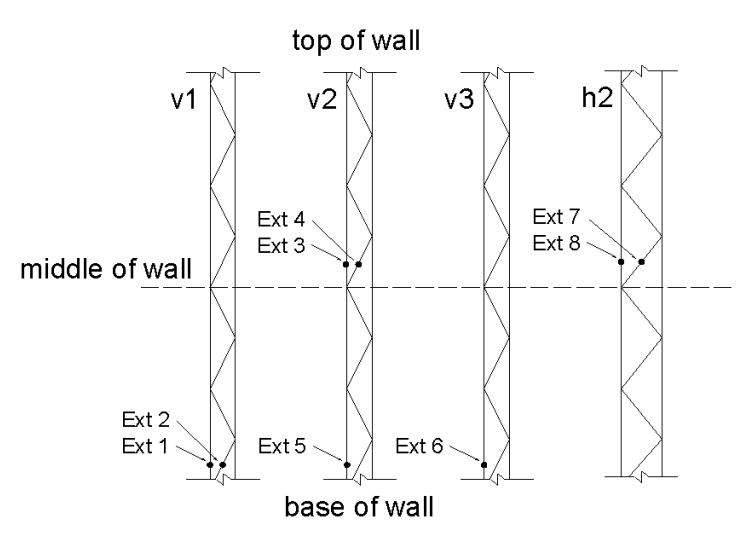

(b)

Fig. 3 - Instrumentation of the in-plane walls: (a) LVDTs to measure the displacements of the walls: (b) strain-gauges to measure the strain on the reinforcement. 




Fig. 4 - Imposed displacement-time history.

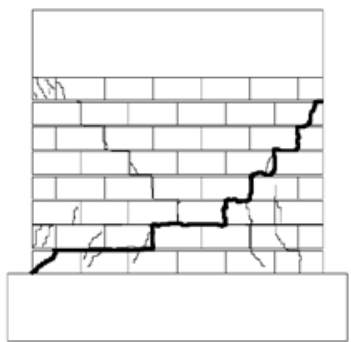

N60-B1-UM

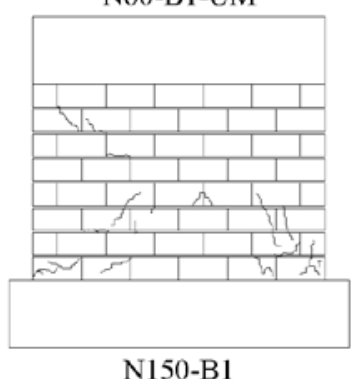

N150-B1

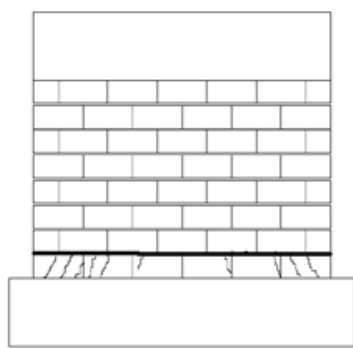

N60-B1-SH



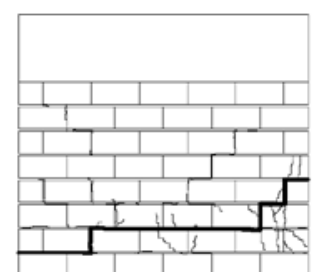

N60-B1

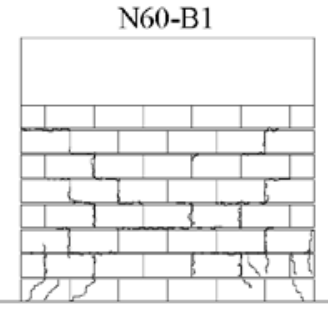

N60-B1-MA

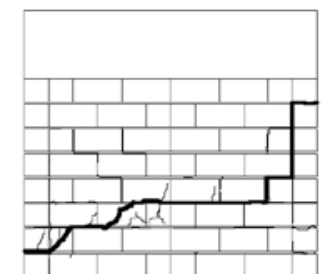

N60-B2

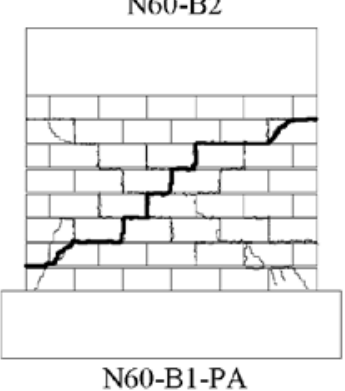

Fig. 5 - Masonry wall cracking patterns. 


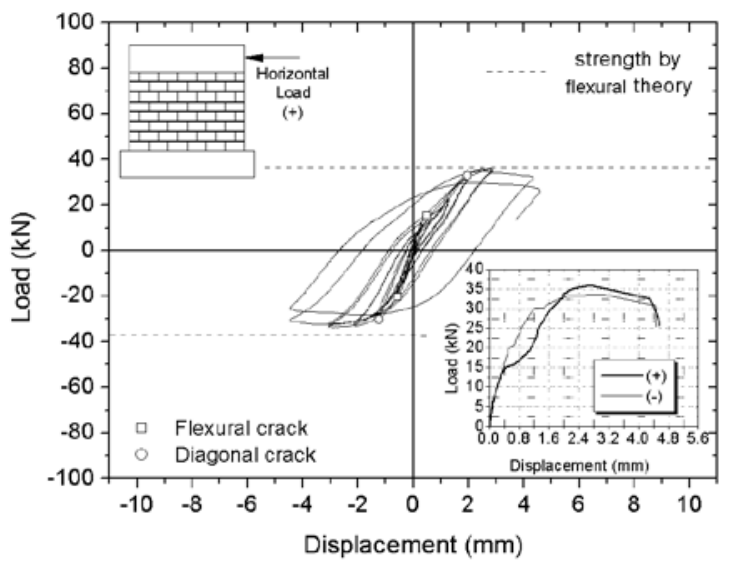

(a)

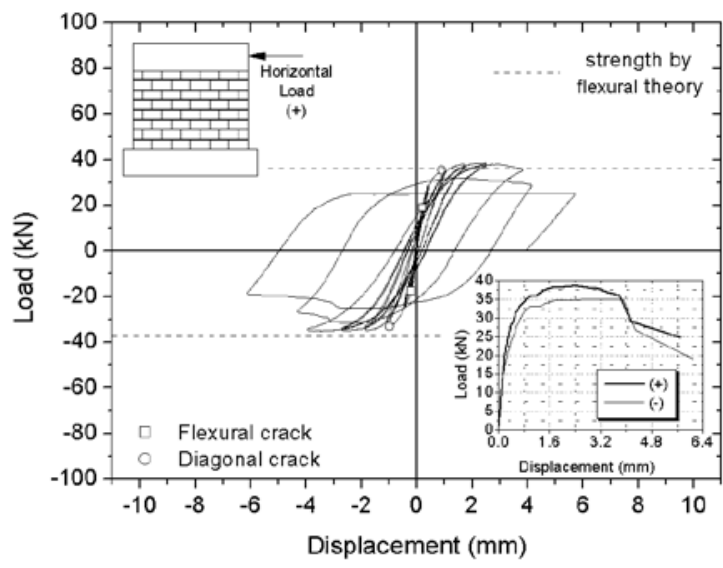

(b)

Fig. 6 - Force vs. displacement diagrams: (a) N60-B1-UM and (b) N60-B1-SH.

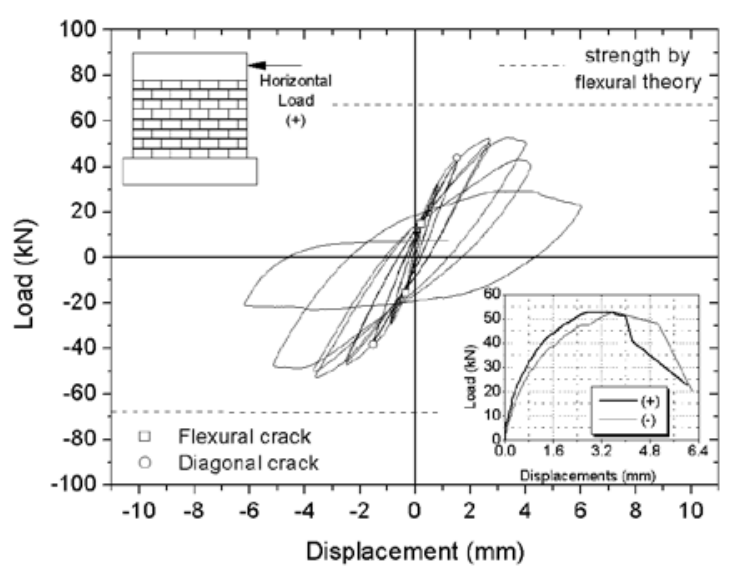

(a)

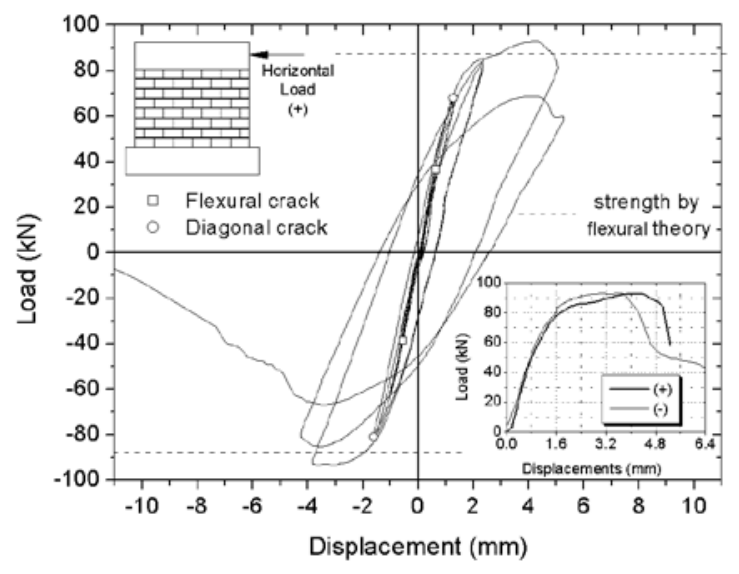

(c)

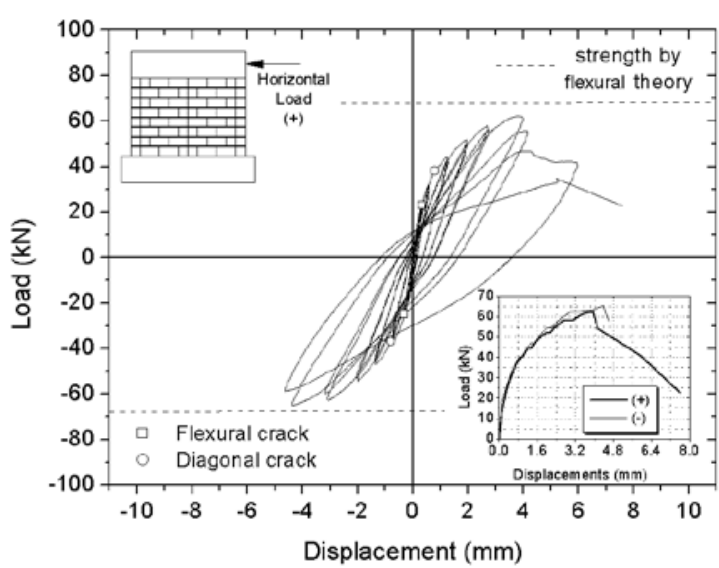

(b)

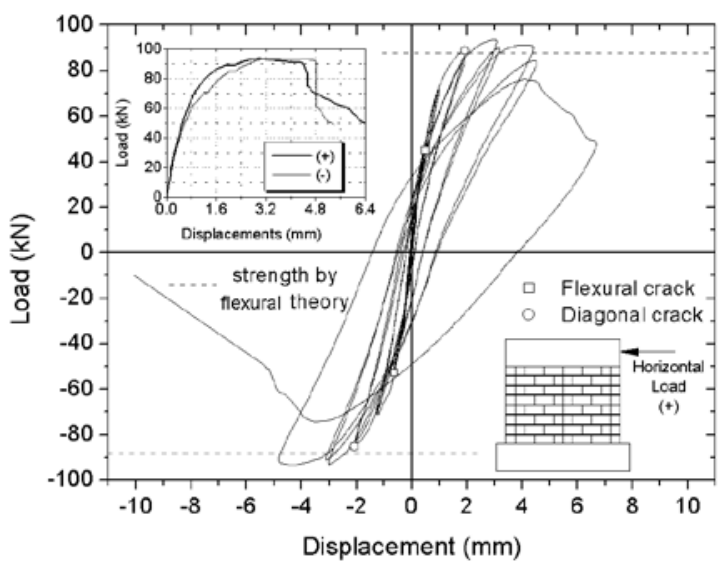

(d)

Fig. 7 - Force vs. displacement diagrams: (a) N60-B1, (b) N60-B2,

(c) N150-B1 and (d) N150-B2. 


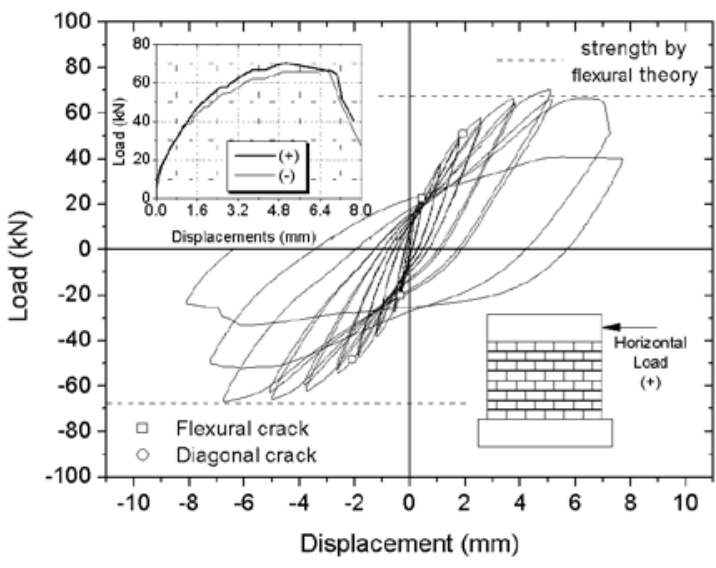

(a)

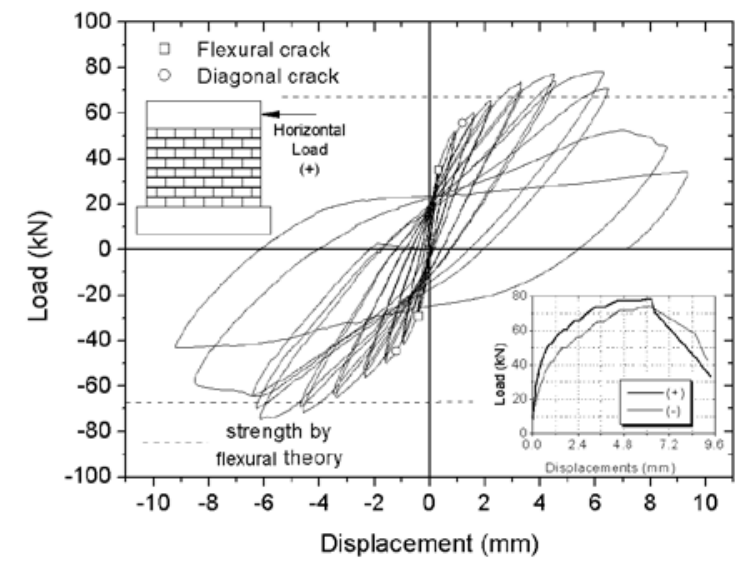

(b)

Fig. 8 - Force vs. displacement diagrams: (a) N60-B1-PA and (b) N60-B1-MA.

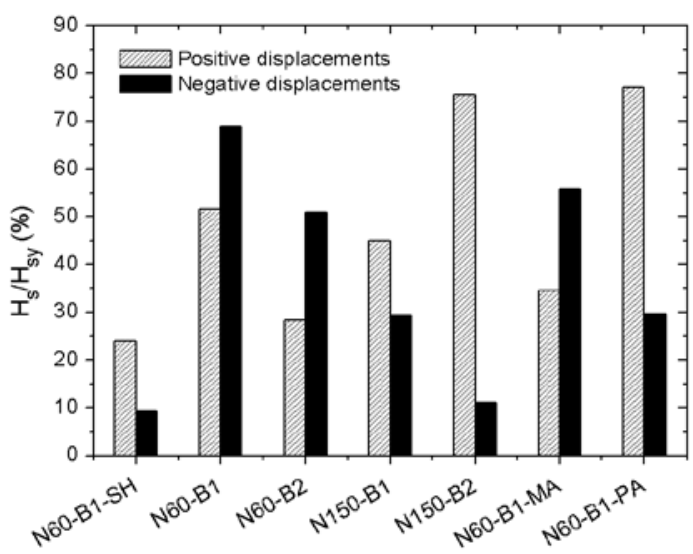

(a)

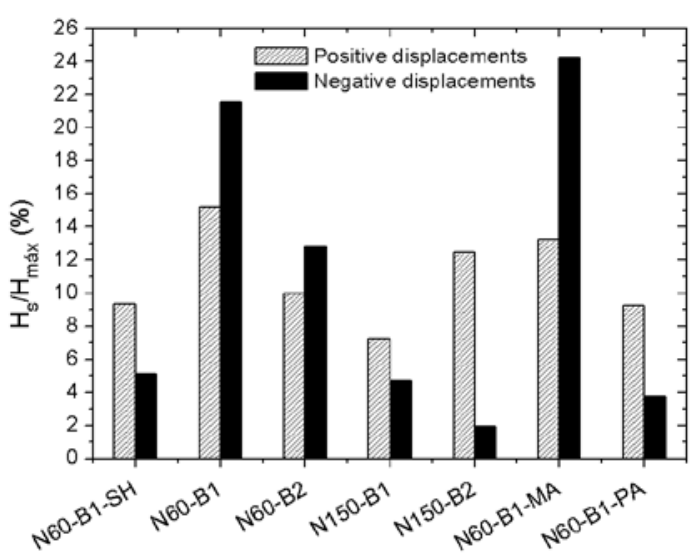

(b)

Fig. 9 - Efficiency of horizontal reinforcement at wall peak load: (a) percentage of the force in the reinforcement with respect to the yield force and (b) ratio between the force in the reinforcement and the lateral applied force 


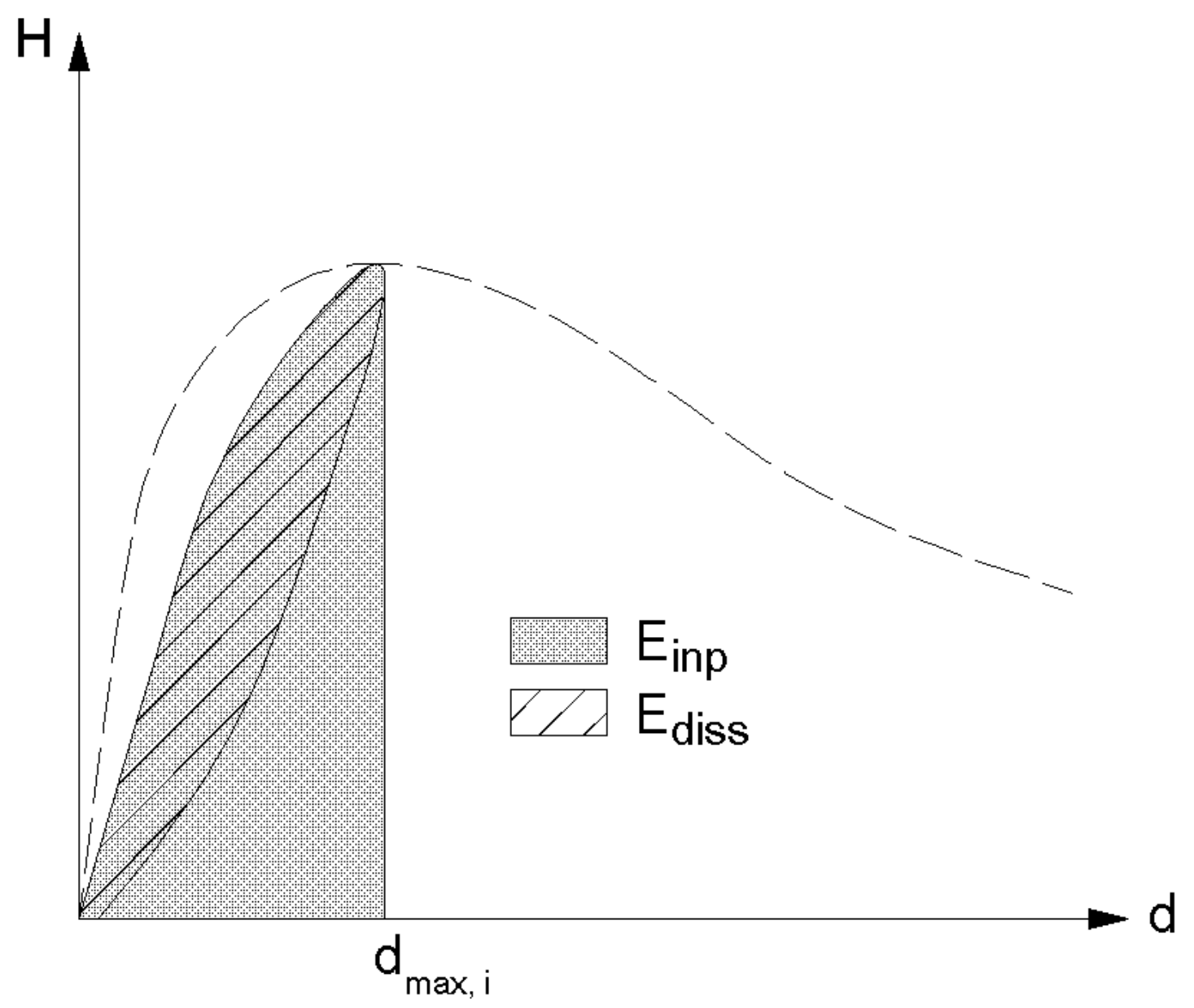

Fig. 10 - Evaluation of energy in one loading positive cycle. 


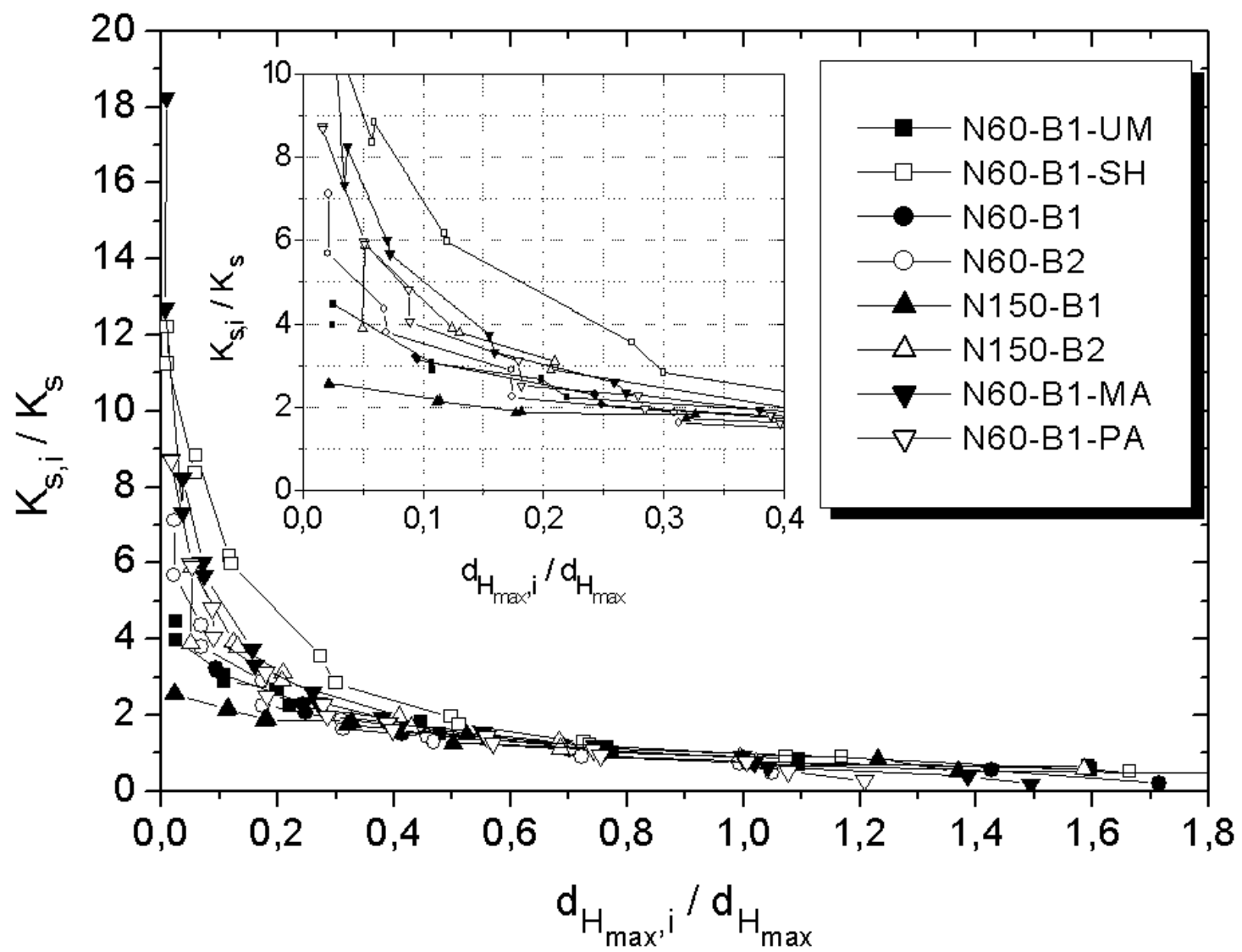

Fig. 11 - Evolution of stiffness degradation. 


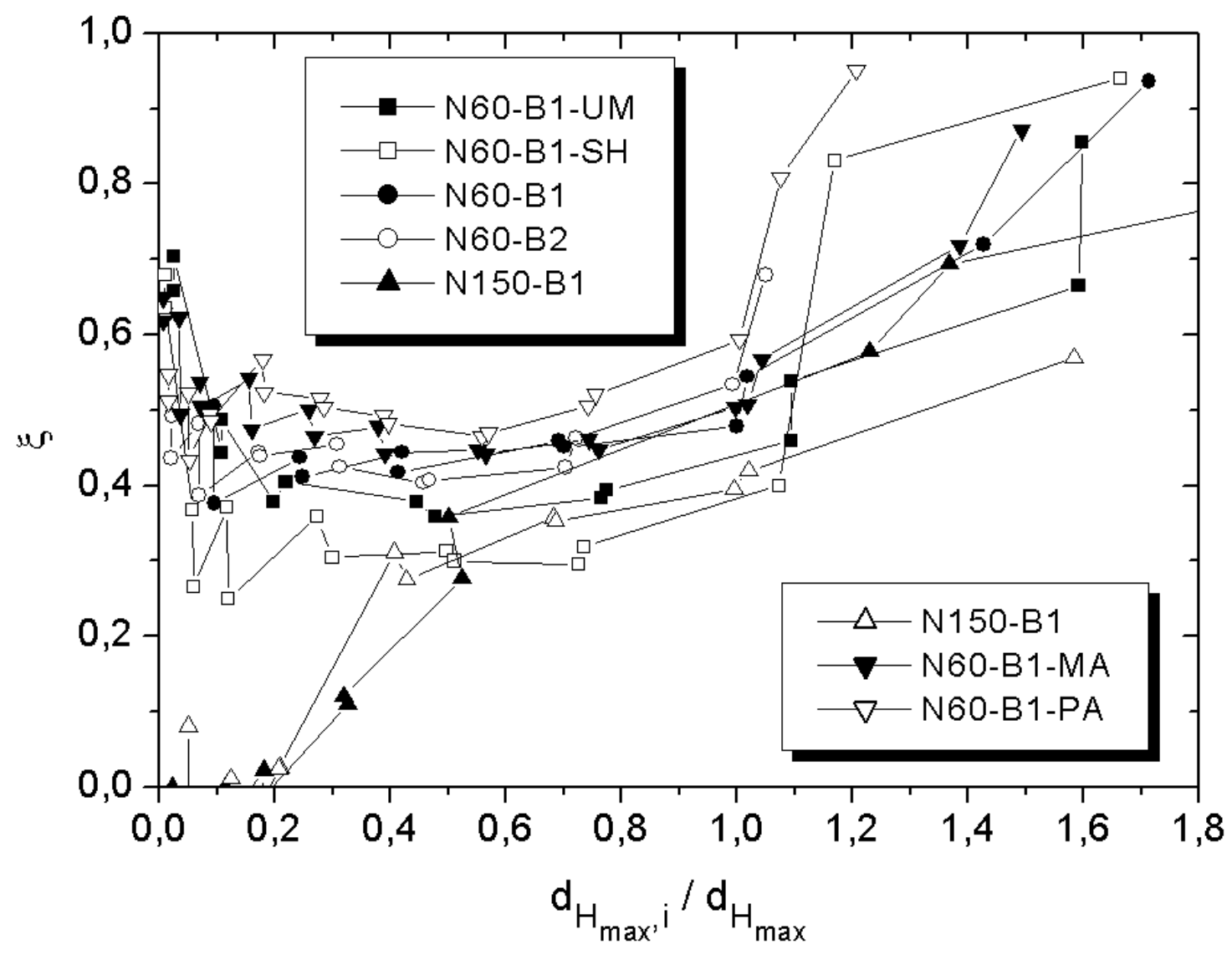

Fig. 12 - Coefficient of equivalent viscous damping ( $\xi$ ) 


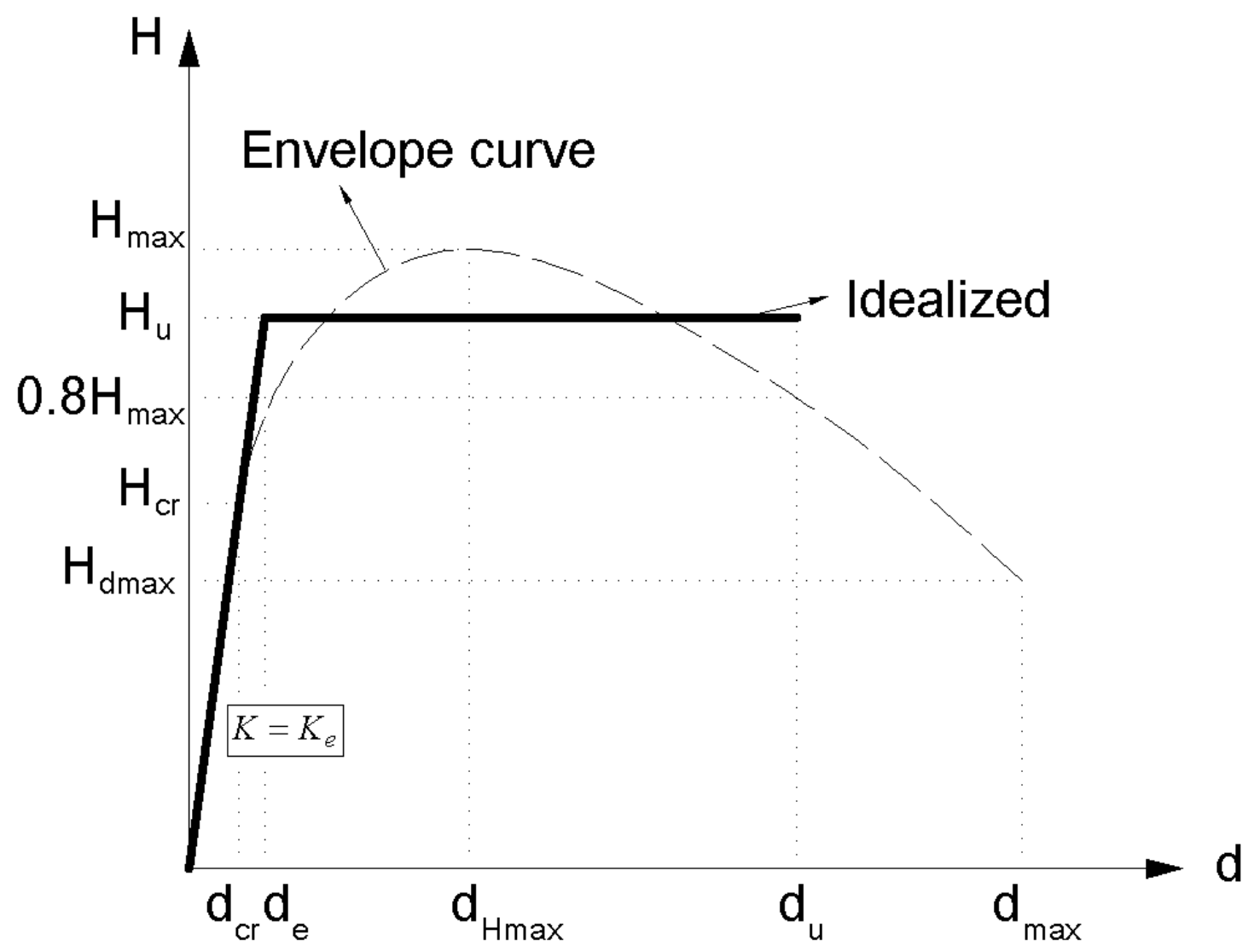

Fig. 13 - Bilinear idealized diagram (Tomaževič (1999)). 


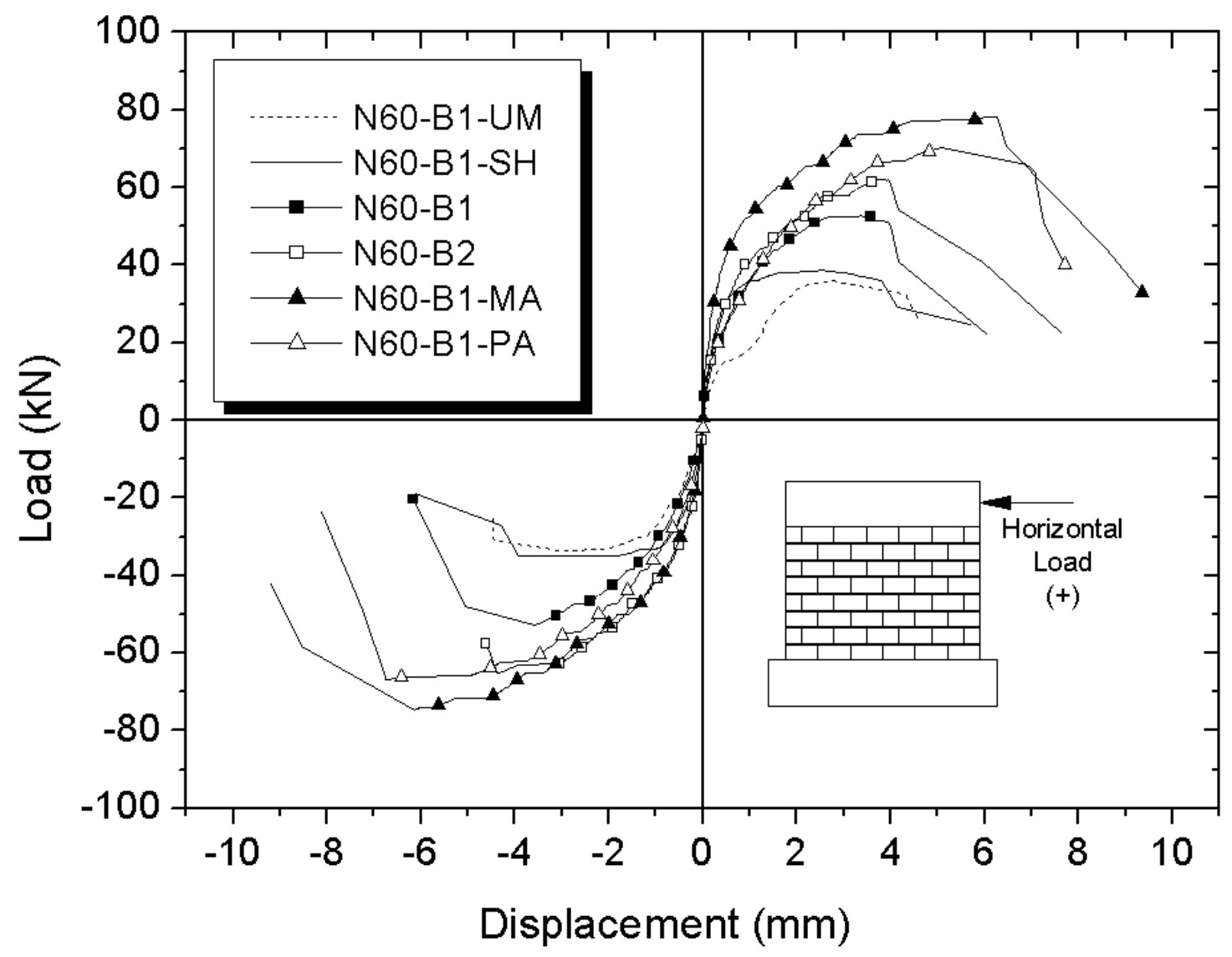

Fig. 14 - Influence of horizontal reinforcement on lateral strength. 


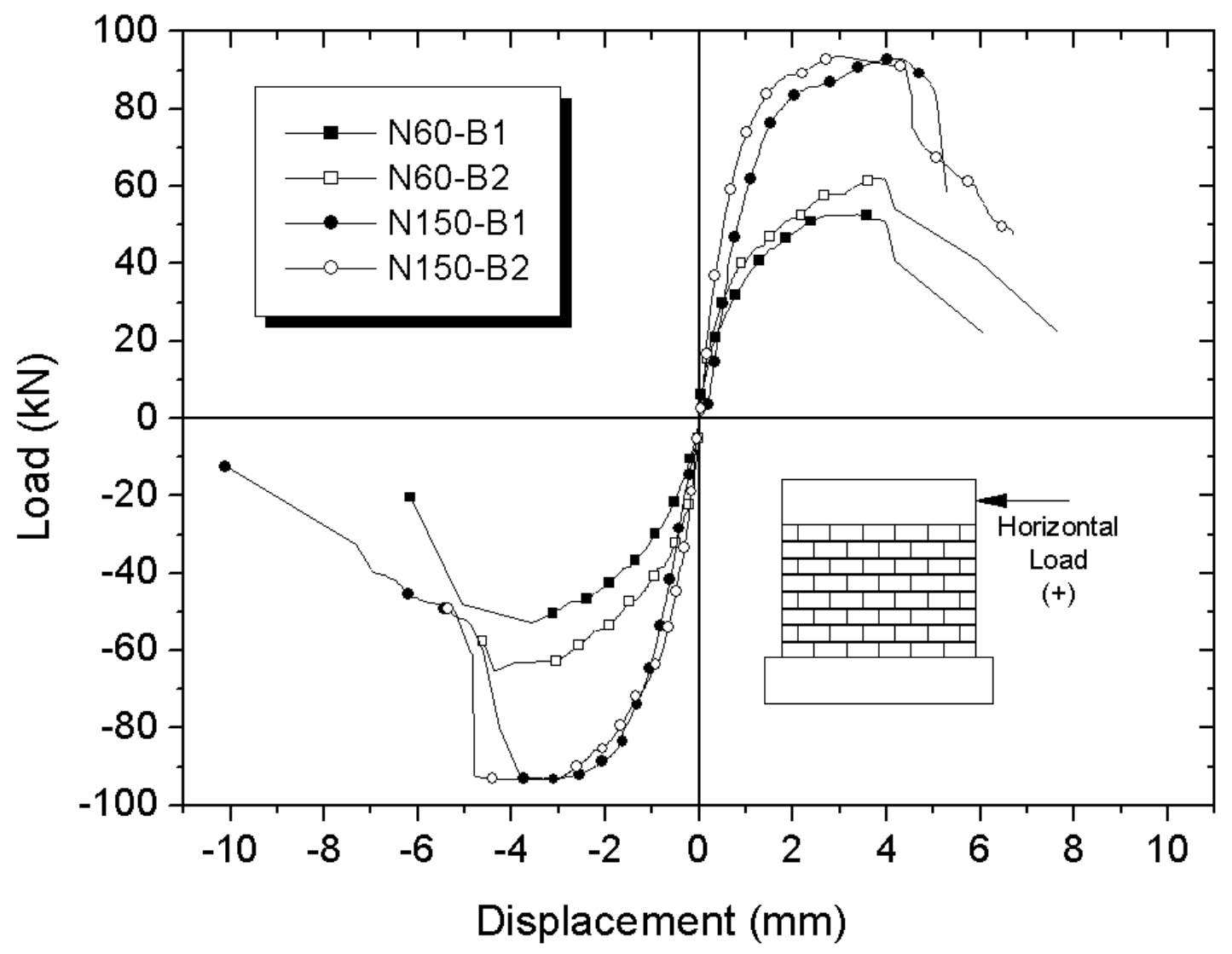

Fig. 15 - Influence of pre-compression and masonry bond pattern on lateral strength. 
Table 1 - Masonry specimens

\begin{tabular}{ccccccc}
\hline Wall & $\begin{array}{c}\text { Masonry } \\
\text { bond }\end{array}$ & $\begin{array}{c}\phi_{\mathrm{v}} \\
(\mathrm{mm})\end{array}$ & $\begin{array}{c}\rho_{\mathrm{v}} \\
(\%)\end{array}$ & $\begin{array}{c}\phi_{\mathrm{h}} \\
(\mathrm{mm})\end{array}$ & $\begin{array}{c}\rho_{\mathrm{h}} \\
(\%)\end{array}$ & $\begin{array}{c}\sigma \\
(\mathrm{MPa})\end{array}$ \\
\hline N60-B1-UM & B1 & - & - & - & - & 0,56 \\
\hline N60-B1-SH & B1 & - & - & 4 & 0,094 & 0,56 \\
\hline N150-B1 & B1 & 5 & 0,098 & 4 & 0,094 & 1,30 \\
\hline N150-B2 & B2 & 5 & 0,098 & 4 & 0,094 & 1,30 \\
\hline N60-B1 & B1 & 5 & 0,098 & 4 & 0,094 & 0,56 \\
\hline N60-B2 & B2 & 5 & 0,098 & 4 & 0,094 & 0,56 \\
\hline N60-B1-PA & B1 & 5 & 0,098 & 3 & 0,053 & 0,56 \\
\hline N60-B1-MA & B1 & 5 & 0,098 & 4 & 0,126 & 0,56 \\
\hline
\end{tabular}

Table 2 - Summary of mortar characterization and elastic modulus of the shear walls

\begin{tabular}{cccc}
\hline Wall & $\begin{array}{c}f_{m} \\
(\mathrm{MPa})\end{array}$ & $\begin{array}{c}\mathrm{f}_{\mathrm{fil}} \\
(\mathrm{MPa})\end{array}$ & $\begin{array}{c}\mathrm{E}_{\mathrm{a}, \text { exp }} \\
(\mathrm{GPa})\end{array}$ \\
\hline N60-B1-UM & 3,58 & 1,21 & 5,10 \\
\hline N60-B1-SH & 5,16 & 1,55 & 9,79 \\
\hline N60-B1 & 3,82 & 1,27 & 7,10 \\
\hline N60-B2 & 7,11 & 1,87 & 8,00 \\
\hline N150-B1 & 8,62 & 2,75 & 7,90 \\
\hline N150-B2 & 7,72 & 2,63 & 8,10 \\
\hline N60-B1-PA & 4,82 & 1,49 & 13,93 \\
\hline N60-B1-MA & 5,16 & 1,53 & 9,30 \\
\hline
\end{tabular}

Table 3 - Critical loads of wall specimens for different stages

\begin{tabular}{ccccccc}
\hline Wall & \multicolumn{2}{c}{$\begin{array}{c}\text { Flexural } \\
\text { cracking } \\
(\mathrm{kN})\end{array}$} & \multicolumn{2}{c}{$\begin{array}{c}\text { Diagonal } \\
\text { cracking } \\
(\mathrm{kN})\end{array}$} & $\begin{array}{c}\text { Maximum } \\
\text { Load } \\
(\mathrm{kN})\end{array}$ \\
\hline N60-B1-UM & $-20,33$ & $+15,33$ & $-30,20$ & $+32,76$ & $-33,63$ & $+35,88$ \\
\hline N60-B1-SH & $-17,56$ & $+18,93$ & $-33,13$ & $+35,40$ & $-35,09$ & $+38,61$ \\
\hline N60-B1 & $-15,66$ & $+14,78$ & $-38,42$ & $+43,80$ & $-52,75$ & $+52,73$ \\
\hline N60-B2 & $-24,82$ & $+22,95$ & $-36,97$ & $+38,21$ & $-65,18$ & $+62,09$ \\
\hline N150-B1 & $-38,57$ & $+36,59$ & $-80,98$ & $+67,86$ & $-93,22$ & $+92,98$ \\
\hline N150-B2 & $-52,81$ & $+45,07$ & $-85,35$ & $+88,96$ & $-93,28$ & $+93,80$ \\
\hline N60-B1-PA & $-20,05$ & $+22,47$ & $-48,26$ & $+50,73$ & $-66,92$ & $+70,22$ \\
\hline N60-B1-MA & $-29,21$ & $+34,85$ & $-44,68$ & $-55,48$ & $-74,59$ & $+78,36$ \\
\hline & & & & & &
\end{tabular}


Table 4 - Summary of results of bilinear idealization of masonry walls.

\begin{tabular}{|c|c|c|c|c|c|c|c|c|c|}
\hline Wall & $(+I-)$ & $\begin{array}{l}\mathrm{H}_{\mathrm{cr}} \\
(\mathrm{kN}) \\
\end{array}$ & $\begin{array}{c}\mathrm{d}_{\mathrm{cr}} \\
(\mathrm{mm})\end{array}$ & $\begin{array}{c}K_{\mathrm{e}} \\
(\mathrm{kN} / \mathrm{mm}) \\
\end{array}$ & $\begin{array}{l}\mathrm{K}_{\mathrm{e}, \mathrm{t}} \\
\mathrm{kN} / \mathrm{n}\end{array}$ & $\begin{array}{r}\mathrm{H}_{\mathrm{u}} \\
(\mathrm{kN}) \\
\end{array}$ & $\begin{array}{c}d_{e} \\
(\mathrm{~mm})\end{array}$ & $\begin{array}{c}d_{u} \\
(\mathrm{~mm})\end{array}$ & $\mu$ \\
\hline \multirow{2}{*}{ N60-B1-UM } & + & 15,33 & 0,48 & 31,94 & \multirow{2}{*}{170,16} & 31,28 & 0,98 & 4,47 & 4,56 \\
\hline & - & 20,33 & 0,56 & 36,62 & & 31,78 & 0,87 & 4,45 & 5,13 \\
\hline \multirow{2}{*}{ N60-B1-SH } & + & 18,93 & 0,20 & 95,47 & \multirow{2}{*}{326,63} & 33,53 & 0,35 & 4,12 & 11,73 \\
\hline & - & 17,56 & 0,21 & 82,29 & & 30,06 & 0,37 & 4,23 & 11,58 \\
\hline \multirow{2}{*}{ N60-B1 } & + & 14,78 & 0,22 & 66,85 & \multirow{2}{*}{236,88} & 41,34 & 0,62 & 4,16 & 6,73 \\
\hline & - & 15,66 & 0,34 & 45,50 & & 43,16 & 0,95 & 5,29 & 5,58 \\
\hline \multirow{2}{*}{ N60-B2 } & + & 22,95 & 0,32 & 71,72 & \multirow{2}{*}{267,70} & 46,30 & 0,65 & 4,77 & 7,39 \\
\hline & - & 24,82 & 0,32 & 77,56 & & 55,76 & 0,72 & 4,80 & 6,68 \\
\hline \multirow{2}{*}{ N150-B1 } & + & 36,59 & 0,64 & 57,17 & \multirow{2}{*}{263,57} & 86,19 & 1,51 & 5,13 & 3,40 \\
\hline & - & 38,57 & 0,56 & 68,88 & & 73,04 & 1,06 & 4,36 & 4,11 \\
\hline \multirow{2}{*}{ N150- } & + & 45,07 & 0,48 & 93,90 & \multirow{2}{*}{267,70} & 78,49 & 0,84 & 4,82 & 5,77 \\
\hline & - & 52,81 & 0,64 & 82,52 & & 83,34 & 1,01 & 4,58 & 4,53 \\
\hline \multirow{2}{*}{ N60-B1-MA } & + & 34,85 & 0,32 & 108,91 & \multirow{2}{*}{464,76} & 63,93 & 0,59 & 7,11 & 12,11 \\
\hline & - & 29,21 & 0,40 & 73,03 & & 61,99 & 0,85 & 8,31 & 9,79 \\
\hline \multirow{2}{*}{ N60-B1-PA } & + & 22,47 & 0,42 & 53,72 & \multirow{2}{*}{310,28} & 60,08 & 1,12 & 7,18 & 6,42 \\
\hline & - & 20,05 & 0,34 & 59,23 & & 54,46 & 0,92 & 7,11 & 7,73 \\
\hline
\end{tabular}

